Portland State University

PDXScholar

$4-1-1968$

\title{
A series of paintings, both Oriental and Western, oriented toward a combination of the Western and Oriental styles in the use of mixed media
}

Young Hie Shin

Portland State University

Follow this and additional works at: https://pdxscholar.library.pdx.edu/open_access_etds

Let us know how access to this document benefits you.

\section{Recommended Citation}

Shin, Young Hie, "A series of paintings, both Oriental and Western, oriented toward a combination of the Western and Oriental styles in the use of mixed media" (1968). Dissertations and Theses. Paper 476. https://doi.org/10.15760/etd.476

This Thesis is brought to you for free and open access. It has been accepted for inclusion in Dissertations and Theses by an authorized administrator of PDXScholar. Please contact us if we can make this document more accessible: pdxscholar@pdx.edu. 
Young Hie Shin for the Master of Science in Teaching in Art Presented on April 19, 1968

Title: A Series of Paintings, both Oriental and Western, Oriented Toward a Combination of the Western and Oriental Styles in the use of Mixed Media. Abstract approved:

After studying both Oriental and Western paintings, I became interested in many different approaches involving composition, color harmony, design, texture, and form. It was my main purpose to explore various painting redia by means of combining materials, techniques, and processes used in the Western and Oriental paintings. The source of my paintings is the sum total of my experience in both Oriental and Western paintings.

Most of the Oriental paintings were either sketched or painted out of my imagination. They are clear realism in the Oriental sense of the work. Most of my Western paintings are either abstract or semi-abstract. Some of them were sketched in the Portland area; especially the diptychs and triptychs of my work reflect my feelings of nature: the cycles of the season, the rich Autumn colors in the fall, and the times of the day. It is not a record of my feelings about a particulax place or moment. Rather it is an accumulation of all the things I have seen, abstracted and organized to express all 
I have ever felt and learned about nature.

History shows that new forms of art have always been found absurd at first and then condemned out of hand by the public at large. Hence, I do not feed on a single dish, do not limit myself to a single cuisine; I am on no diet. I merely like it all. Therefore, as an art teacher with a combination of Western and Oriental art backgrounds, I hope I can teach Korean high school students by means of mixed media in expressing their own ideas for their creative work. Here, I would like to define what my mixed medla mean. By it I mean techniques, materials, and processes used both in Western and Oriental paintings.

In the mixed media I used masonite board, rice paper, canvas; oll, ink, tempera, pastel; sharp pointed orlental and wide Western bristie brushes. I tried to figure out the most economical materials for the Korean student, but it was almost next to impossible to do so. It was simply because some materials easily attainable in my country may not be available in this country and vice versa. They, if any, may be more costly. For instance, rice paper is much. more expensive in this country than in Korea; masonite board is more expensive in Korea than in the United States of America. Therefore, I decided to leave it to my future planning.

Also contained within my thesis are my education objectives for Korean high school students. In Korea the art 
education in high school is still tradition-bound, although the trend is changing gradually toward an improvement in thinking and imagination concerning art. In this sense I would like to emphasize creativity which comes whenever the individual searches for a new solution which is novel, and unique, representing the culmination of a creative act. 
A SARIES OF PAINTINGS BOTH ORIENTAL AND WESTERN, ORIENTED TOWARD A COMBINATION OF THE WESTERN AND ORIENTAL STYLES IN THE USE OF MIXED MEDIA

by

YOUNG HIE SHIN

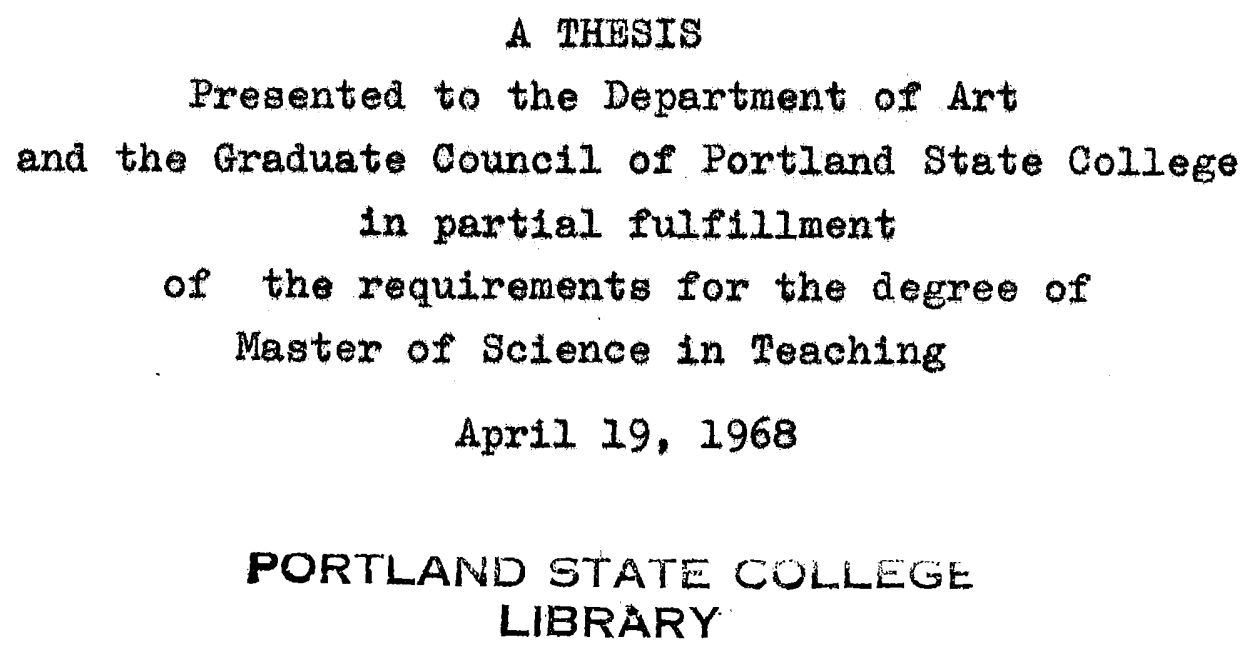

A THESIS

Presented to the Department of Art

and the Graduate Council of Portland State College

in partial fulfillment

of the requirements for the degree of

Master of Science in Teaching

April 19, 1968

PORTLAND STATE COLLEGE

LIBRARY 
APPROVED:

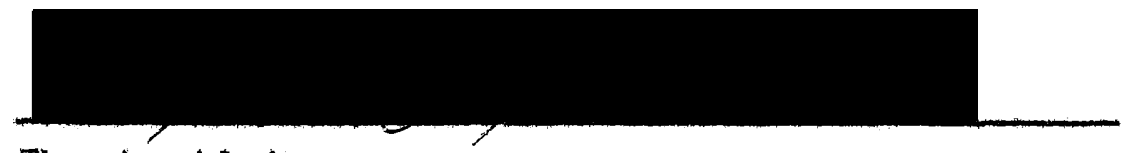

Thesis Adviser

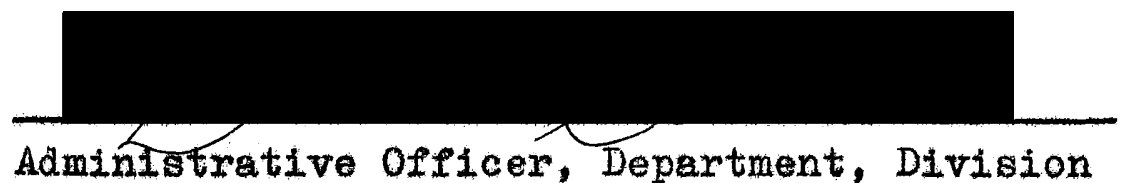
or School

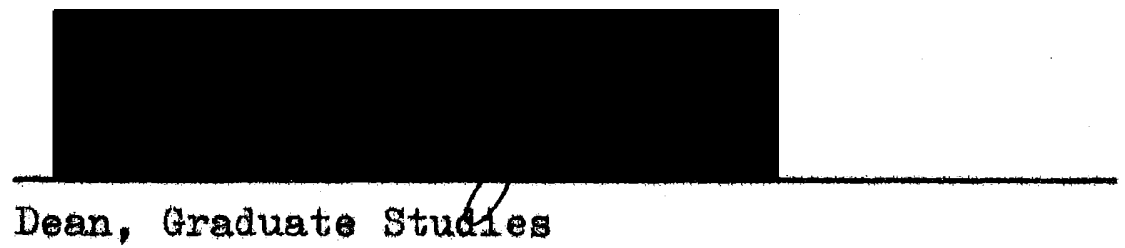

Date thesis io presented: Apri1 19, 1968 
TAELE OF CONTENTS

Page

LIST OF PLATES

INTRODUCTION

1

EDUCATION OBJECTIVES 10

ORIENTAL PAINTING 14

WESTERN PAINPING 19

MIXED MISDIA

$\begin{array}{ll}\text { PLATES } & 27\end{array}$ 


\section{ORIENTAJ PAINTINGS}

Plate

1 Bamboo. Black ink on rice paper.

2 Orchid.

3 Ohrysanthemum

4 PIum-blossoms

5 Crane

6 Wild Geese

$\begin{array}{cc} & \text { Page } \\ 50-1 / 8 \times 13 & 27\end{array}$

$50-1 / 8 \times 13 \quad 27$

$50-1 / 8 \times 13 \quad 27$

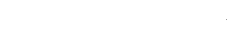

$"$

$50-1 / 8 \times 13$

$50-1 / 2 \times 13$

$49-1 / 4 \times 13$

27

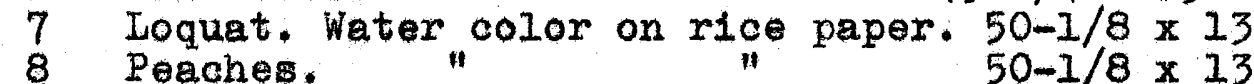

28 $50-1 / 8 \times 13 \quad 29$

9 Lotus. "

10 Birds \& Lotus.

$36-1 / 2 \times 11$

$16-3 / 4 \times 11$

11 Iobster. Black ink on rice paper. $13 \times 17$

12 Landscape. Water color on rice paper.17 $\times 25 \frac{1}{2}$

13. Chinese Calligraphy. Black ink. 50-3/4 x $7-3 / 4$

14 Chinese Calligraphy. "

15 Korean Calligraphy. " $\quad 8-1 / 2 \times 17 \frac{1}{2}$

16 Korean Calligraphy. " $8-1 / 2 \times 17 \frac{1}{2}$

28

29

30

30

31

\section{WESTERN PAINTINGS}

17 Autumn. 011 on canvas. $36-3 / 4 \times 48$

18

19

$36-3 / 4 \times 48$

Autumn.

D1ptych

Summer:

$20 \times 26$

$20 \times 26$

Autumn.

$20 \times 26$

Three Seasons."

Iriptych

24 Spring."
25 Ieaves \& Branches " $28 \times 31$

26 Non-titied. 011 on plastered canvas. $32 \times 42$

27 St. John' Bridge. O1l on canvas. $34 \times 48$

\section{MIXED MEDIA}

29 Wild Lily. Tempera on rice paper. $18 \times 23$

30 Flowers by the lake. Tempera \& Oil on rice papered canvas. $27-5 / 8 \times 36-3 / 8$

31 Pine Tree. Tempera on rice papered masonite.

32 A Flock of birds in the Shrub. Black ink \&

Tempera on rice papered canvas. $37 \times 43$

33 Landscape. Tempera \& gesso on rice papered masonite. $22-7 / 8 \times 25$

34 Seascape. Tempera, Oil, \& Pastel on rice papered 45 masonite. $18 \times 23$

35 Marquam Bridge. Tempera on rice papered masonite. 46

$18 \times 23$

36 Quiet. Oil \& Tempera on cenvas. $36-1 / 4 \times 48$ 
A SERIES OF PAINTINGS, BOTH ORIENTAL AND WESTERN, ORIENTED TOWARD A COMBINATION OF THE WESTERN AND ORIENTAL STYLES IN THE USE OF MIXED MEDIA

\section{INTRODUCWION}

My studies of both Oriental and Western paintings have Ied me to explore new possibilities of mixed media by means of techniques, materials, and processes used in both Western and Oriental paintings. The subjects of most of my Oriental paintings are birds, flowers, flowering plants, and landscapes which were painted either from memory or life or from my imagination. They are, as will be shown in the later portion of this project, all realistic. Most of my Western paintings are either abstract or semi-abstract on which I exerted a great deal of my time and effort in a concentrated search from the solution to the problem of how to represent in terms of paint the complete visual effect of nature by means of form, color, and texture.

In comparison with Western paintings, I tried to fulfill the maximum aesthetic needs with the minimum employment of line, brushstroke, and color, although there are some exceptions in some of my paintings. While working with Western paintings, I came to realize that in many of my Oriental painting, there is no distinction between the space of foreground and background. 
Hence, without any idea of recession the shapes look, so to speak, forced outward to the picture plane, almost like cut-outs pinned to a screen. However, the dominant aesthetio need was, as one may see in every branch of Oriental art, not a precise transoription of nature in the sense of total visual effect, but rather the representation of the essence or spirit peculiar to the manifold creations of the world of nature.

Speaking of composition, Oriental composition is quite characteristic of Far Eastern Art in that it consists of a relationship of isolated compartments as opposed to the Western composition of fused relations. This grouping of elements into compartments leads to the tremendous difference in the character of the solids and voids. In the West the whole surface is covered with many color combinations and as a reault the whole surface $1 \mathrm{~s}$ equally important. In the Orient it is the vold intervals between these isolated groupings which determine harmonious relationships. Therefore, the principles of design in Oriental Art are made of thes time relationships grouping from the interaction of solids, mass, and void.

The relationsh1p to space is abstractly implied by the blank paper surrounding the form. In the Oriental paintings, the combination of brushatrokes is more than a decorative surface pattern. Beyond 1ts intrinsic aesthetic appeal in terms of the aubtle variations in the value of the ink tones, it confers both form and texture on the object portrayed. 
Many of my Oriental paintings are executed on rice paper, either in monochrome ink or in a combination of ink line and opaque water-color pigment. Ink and colors are applied with brush which, in the hand of the Oriental artist, is at once pen or pencil and an instrument of great subtlety for the application of washes in ink or tone. Here, the separate brushstrokes combine to give structure to the forms, and in their pattern impart vivacity and harmony to the painting.

Through the medium of brugh and ink the very fragility of surface and the medium rendered impossible the achievement of the rich effects of color and texture obtainalbe in the Western technique of oil painting. To me the oriental paintings seem to give an impression of watching still pictures more or leas; the Western paintings seem to give an impresaion of watching moving pictures. I think it is for this reason that the oriental painters strove for interpretation of mood and spirit, rather than the rendering of the visual and plastic effects sought after by the Western painters.

The first impression of the Oriental painting is that of very concentrated repregentation of the bird, for instance, Plate $\# 10$, in term of precise strokes and painstaking regard for the elements of color, texture, and form. 
The ink painting of the crane, Plate $\# 5$, was executed with great immediay in the fewest possible strokes. The sure progresalon of the touch of the brush can be followed in its unerring placing on the paper. Just as each stroke is completely satisfying in itself, so the combination of all the strokes together give a good suggestion of the structure of the bird and its texture.

In contrast to Oriental paintings, I would like to discuss many different points on Wegtern Paintings. Painting is a means of giving visual form to 1deas, To ne these ideas seem to spring from the intellect but are formed and molded in the process of creation by experiences, perception, etions and the unconscious. Often times I hear many people saying "only realism is good" or "only abstraction is good". I think they are interested in fashion, not painting. I like many kinds of paintings. It is the quality of the work that counts. In transferring the idea from drawing to canvas, color plays a major role in involving the viewer emotionally and intellectually in painting. Color is the vehicle by which the design is usually executed. Therefore, the drawing is conditioned or altered as the design requires. Also, the proper diatribution of color is regulated by the design.

A number of Western paintings done in this country at the beginning of oil painting were much more realistic than those done lately. 
For me it was not easy to obliterate a lot of detail in the Western style painting. However, this problem was easily solved, because most of my Western paintings submitted here are abstract designs acting as a structural basis for the presentation of subject matter.

Nature has always beon my model. I do not copy nature, but I borrow and compose to make an interesting design. As to color, I use my own ideas through a series of experiments. When I first started Western painting, the real problem that I was confronted with was not the question of how to paint, for instancea, ggs in a white bowl on a white cloth, but to include harmonious colors in the painting that will give the total effect. In Oriental painting, harmonious colorg-m reflected from the background-do not seem to be emphasized as in Westem painting. Furthermore, in case we have some undesirable strokes appearing, we cannot go over to correct them. So, if strokes do not turn out exactiy as one wants it, he is not supposed to go over to correct them. In addition to that, mostly we leave background in the painting unpainted. That was why it was so hard for we to relate the object to the background harmon1ously.

However, a series of landscape in oll painting and other media exploring and interpreting natural landscape helped me find the means of harmonizing colors and forms. It is the rhythmic movement of these forms and colors that reflects the constant change and movement of nature. 
I believe that one's attention begins to be centered on the effects of the total landscape-effects of color changes, rhythm and movement, form relationships, spatial relationships, and atmospheric effect that are to be found in nature itself. The diptych landscape, Plate \#19, the diptych landscape, Plate \#24, and the triptych landscape of Plate \#23 (Sumer, Autumn and Winter) are good examples, the color combinations of which I beliove came out quite successfully.

Picasso said that art and nature are two different realitites and that, although they are closely inter-related, art is not merely the representation of nature. Nature and art, being two different things, cannot be the same thing. I agree with him. I belleve that as long as the harmony of color and design are pleasing and nature is not twisted, the painting should or can be justified.

Sometimes the color is important, sometimes the shape or the mathematical relationship of parts, and likewise texture. For example, Plate \#26 is not only a study of color but also of texture. After a coat of Gesso was applied as a base on the canvas, gesso mixed with glue made out of flour(its making procedure shown later) was thrown at the canvas in a certain way as my foelings told me so as to get some textures. This painting gives a visual effect rather than the meaning of the subject. Pure abstraction does not tell a story even though it may have design, color, texture, etc. 
It leaves almost everything up to the viewer's imagination. Through this painting, I found textures very exciting, and that paint quality, texture, and design meen more to me than the subject matter.

In Oriental painting, there is one preliminary step that requires many diligent years and accounts for one important feature; the most 1mportant thing is the close relationship between painting and calligraphy. In both arts the same soft, pointed brush 1 used with a consequent emphasis on high standards of brushwork. We can find many interesting brush strokes in Korean and Chinise characters that will help produce variety and quality of line, which will in turn produce exacting requirements in the shape, texture; point, and flexibility of the brush.

For my exploration for new mixed media, the great command of the use of brush and ink, plus what I have learned in Western painting made it posalble for me to discover a few things. The first mixed media painting is Plate \#32, 'A flock of blrda in the shrub', executed on the rice paper pasted canvas on which I used ink, pigment, 011 , and a touch of tempera. This painting was done on the basis of the medium of brush and ink--exclusively Oriental brush strokes for the birds and trees and a little touch of Western brush strokes were added in the sky. Through writing or painting with brugh and ink for many years, I could acquire sensitivity and control of the medium because both Chinise and Korean characters involve many delioate lines and details. 
Plate \#32, 'A flock of birds in the shrub', was painted on an old painting over which one sheet of rice paper was pasted with glue made out of flour. I discovered that it is wiser to start painting on it after the rice paper dries up. Otherwise, the color may look discolored afterwards. Previously I had an experiment of painting on the rice paper covered canvas in a state of wet. The first time it seemed to have come out quite successfully, but looked as if it were discolored, The following is how I make glue out of flour:

4 Table spoons flour

2 Cups water (either warm or cold water not bolling water)

Pour water into flour and $\mathrm{mix} 4$ table spoons flour with $\frac{1}{2}$ cup water and stir till soft Iiquid and then add $1 \frac{1}{2}$ cups water in 1 t. Heat under medium heat, stirring constantly till mixture comes to boiling. It takes approximately $12-13$ minutes.

Another discovery I made in doing the serles was that the traditional mounting of paintings in silk or paper can be substituted by masonite board and rice paper, although this can not be rolled or unrolled or stored as the oriental scroll. In Korea, paintings are sent to the professional frame shop where professional people mount the painting with extreme care. Under the present circumstances in Korea, it is not easy to have all the necessery equipment installed in a private home. It is not only costly, but also complicated in the process from start to end. I think that framing is an art, too. 
Therefore, I would like to teach my students how to finish paintings from start to finish, without anybody's help. However, the use of masonite board as a substitute for the traditional mounting of paintings in silk or paper is almost impossible, because of the difference in price between the two countries. Therefore, an attempt was made to solve this problem only under the situation of my being in this country,

As to preparing a rice paper pasted masonite board, the following is the instruction that was developed through my experience and experiment:

Apply Gesso on the masonite board and also the back alde of the panel to prevent warping. Paste a piece of rice paper on the gesso applied board and set it up until it completely dries up.

Both sides of the panel can be used. But I discovered that the rough side provides an ideal surface for producing textures. 
MY EDUCATION OBJECTIVES FOR

KOREAN HIGH SCHOOL STUDENTS

\begin{abstract}
The aim of education should be to convert the mind into a living fountain and not a reservoir. That which is filled by merely pumping in, will be emptied by pumping out.-John M. Mason
\end{abstract}

As an art teacher with a combination of Weatern and Oriental art backgrounds, I hope I can teach Korean high school students by means of mixed media in expressing their own ldeas for thelr ereative works. I discovered through many experiments that teaching by means of mixed media might help develop many new ideas of a wide range in art.

In my country, often times students are asked to approach the subject of art in certain specific ways which I think are likely to inhibit creative art. I certainly believe that tudents should be encouraged to discover and search for their own answers, instead of pasgively walting for answers and directions from the teacher. As an art teacher I would like to create the opportunity for the student to produce art with his present knowledge.

Often timer I have wondered what the bases are for judging a prize-winning work of art. Now, I realize that for a work to have lasting importance it requires that the artist use the most effective means to realize his idea or visual experience. Thus, I would like to emphasize that the Idea is the very essence of a work of art, and that to become a fine work of art the idea must be clarified and 
resolved so that the work ultimately has its own existence-m the reflection of the sensibility of the artist.

Often times, when I go to museums or art exhibitions, I am at a loss to understand certain art works and wish to know on what basia one can judge art work. I imagine there is no single set of standard a critic can bring to hia intellectual and aesthetic judgment. Therefore, he has to know the fleld well enough to know which set of standards to apply and where. For instance, the "Bull's Head" by Plcasso consists of nothing but the seat and handlebars of an old bicycle. However, he was the first artist who put them together in this unique way. Even though the handiworkthe mounting of the seat on the hendlebars-is ridiculously simple. I strongly believe this came from a creative idea. The visual arts, those which are seen, are concerned With the creative manipulation of materials and elements such as line, color, and form. Creativity implies bringing into existence new constructions through original arrangements involving existing or new elements. In Korea the art education in high school is tradition-bound, although the trend is changing gradually in thinking and imagination concerning art. In my teaching, I would like to emphasize creativity which comes whenever the individual searches for his own solutions to problems in art. The solution which 1a novel, yet based on a knowledge of the past represents the culmination of the creative act. Hence, I would like to 
emphasize in my teaching that flexibility in thinking and imagination in the selection of materials and in their use should be encouraged, without necessarily having to stick to traditional approaches. For instance, collage is an art which refers specifically to the assembling, arranging, and pasting of pieces of paper, cloth, and other materials to create an artiatic composition. Such materials as fragments of wood, stone, or metal, sand or gravel, pleces of paper, magazine, and cloth can be easily obtainable even in a poor country. Students can be taught a great deal in workIng with these materials. Each individual should be encourageed to express his own 1deas. The student accustomed to depending on given patterns will thus be thrown upon his own creative devices in a new and inaccustomed medium and process.

It is quite possible that experimentation in many kinds of media might prove both interesting and valuable. I surely belleve that the more media, techniques, and processes a student works with, the greater his appreciation of art, and the more possibly he may develop new creative ideas. As a future art teacher, I feel that I should be ready to direot students in a fashion to help them to adjust themselves to new situation which requires flexibility in thinking as well as in imagination. I think that creativity is the life-blood of art. To be a good artist one must see many eities, men and things, An art education has no beginning and no end. Not only students, but also teachers 
should look and look, and think and listen, and be aware, draw, and paint, and learn to work. 


\section{ORIENTAI PAINTINGS}

\section{PLATE 1}

In Plate 1 , the intent was to create the vertical brush strokes by means of the techniques of calligraphy, requiring entirely arm movement which must be decisive and strong. The bamboo shows that the composition of the painting depends to a great extent on the void and the arrangement of its criss-crogs Ieaves. In Korea, bamboo signifies a perfect gentleman who is upright and humble. This simple theme gives a chance for the brush to move freely and for the artist to find fresh inspiration in the varied rendering of a familiar design.

\section{PLATE 2}

In Plate 2, Orchid, an attempt was made to show what we call Iines of rhythm. This was painted in monochrome ink only. The simplicity of this painting is balanced by the many tones of ink that appear in the single stroke of the long leaf. The flower was painted with diluted ink that makes the tone of the flower look lighter in color. 


\section{PIATE 3}

Every petal of Plate 3, Chryganthemum was painted in modulated ink outline. The three big blossoms at the bottom and four blossoms, two big and two small were well balanced in composition. The ribs of the leaves were touched with line. The first impression of these blossoms is that they look like real ones, although no color was used.

\section{PIATE 4}

Plate 4, the plum blossoms in winter symbolize a person who can stand the severity of the elements and who has a rugged personality with a firm and unbreakable will. Unlike the bamboo stems in Plate 1 , the branches of the plum tree were crooked and rugged with crevices on the bark. These features can be brought out just by shading the branches with a few irregular lines in dark ink.

\section{PLATE 5}

In Plate 5, the most important thing is line quality. Especially the legs and feet of the crane are good examples showing quality of line, shape, texture, point and flexibil1ty of the brush. The feathers were expressed in dry brush strokes. The wedge-shaped strokes are part of the composition. 


\section{PIATE 6}

In Plate 6, Wild Geese, the most important thing is that the part from head to bottom of the neck was done by one stroke. The gradation of shades was achieved in one single stroke by means of a special technique of dipping the brush in ink of a few containers diluted in different degrees of value.

\section{PLATE 7}

In Plate 7, the interesting thing is that the fruits of loquat were painted with only two strokes plus one dot on the bottom of the fruits. The branches were painted with dry brush strokes. The leaves were painted with vertical, slanting brush strokes, and outlines with darker ink.

\section{PIATE 8}

Plate 8, Peaches, was painted in natural colors except that the background was left unpainted. The bow-like branch with three peaches at the bottom and two above separated the whole picture into three compartmental areas which I think are well balanced in composition. The verse on the left says that it took three thousand years for the peaches to be that delicious looking. Is that not tempting? 
PLATES $9 \& 10$

In Plates 9 \& 10, the lotus gives a fresh and cool feeling. In the leaves, broad wet washes were applied thinly and flat, but with different shades of ink. The flower is soft in texture, delicate in color, clear in form. The very long stroke of the stem, one stroke, almost straight, strong but not stiff, simply indicates line quality again. Plate 10, the bird on the branch sticking out to the left corner shows delicate brush strokes containing textures resulting from using many different colors on the same brush. Wedge strokes simply suggest water around the flowers.

\section{PLATE II}

In Plate II, lobster, the unpainted white background gives a fresh feeling while all the delicate lines involving these two lobsters came out sucessfully. The bodies of the lobsters were done with short dragging strokes with different shades of ink and many delicate lines. The tonality of ink is getting lighter from the head toward the tail, giving a feeling of movement. 


\section{PLATE 12}

This painting, Plate 12 , is to show the refined picturesque design and character of the brush strokes. This gives an impression that it is a gentle and poetic world. Through this painting, one can see various Oriental brush strokes: blunt stroke, delicate stroke, light and heavy strokes, graded soggy strokes, and dry brush strokes. To paint landscapes one should know how to paint tree, trunk, main branches, and then to do the foliage eventually to depict a Iuxuriant forest.

\section{PLATES $13,14,15, \& 16$}

Included here are two scrolls with Chinese characters and two paintings with Korean characters. These are simply to show the graceful characters of Korean and Chinese words full of complicated strokes. There is a very close relationship between painting and calligraphy: in both arts the same soft, pointed brush is used with a consequent emphasis on high standards of brushwork. In writing with brush and ink, one can acquire sensitivity and control of the medium, and because of the nature of Korean and Chinese writing, the finest training of hand and eye. 


\section{WESTERN PAINTING}

\section{PIATES $17 \& 18$}

Two abstract paintings of Autumn, Plates 17 and 18 were combined into a diptych. As to color, an attempt has been made to produce a warm feeling in Plate 18; the color of the moon was painted in orange, while the blue moon in Plate 17 gives a cool feeling.

In this diptych I tried to put in all the elements of natural colors in Autumn. Those strong free strokes in the sky give a feeling of movement so that the eyes would not fix on one place. Finergetic lines of white were well constructed across the diptych. These lines not only give a feeling of movement, but also make connections with the two pieces to combine into a diptych. This movement is further arrested by the implied lines created by the repetition of many similar forms which seen to move from Plate 17 to Plate 18. Important is the entire painting assuming the character of a composite image of Autumn and all the elements of Auturan colors.

The dynamic strokes in the sky and the rhythmic movement and counter-movement of the forms and colors seem to give vitality to the painting. I think it is those that bring it to Iife. The eye can easily move from one form to another without encountering a boundary line,

\section{PLATE 19}




\section{PLATES 20, 21, and 22}

Originally my attempt was to express four seasons: Spring, Summer, Autumn, and Winter. However, three seasons of Summer, Autumn, and winter were combined into a triptych, because those strokes expressing the feeling of Spring looked rather restricted; all the strokes of the other seasons came out really free in smooth movement. On the triptych, generally, each brush stroke and each color were calculated on the basis of colors that represent each season to produce a desired effect. The hot sun surrounded by warm and cool colors creates an impression that this painting was intended to be sumer. The orange and burnt siena connected to the Autumn.

Autumn symbolizes the falling leaves. Therefore, I used mostly vertical strokes. The use of a slight touch of cool color and all the Autumnal tints increased the visual richness. Plate 21 was composed in terms of aesthetic attraction by the abstract arrangement of the elements comprising the nature of Autumn.

Winter comes after Autumn. Therefore, some Autumn colors were used in the left and suddenly the white space shows up. This area left unpainted--which appears to be covered with white snow and the pale moon in the background of cool colors give an impression that Winter has come to this land. At the right side, the unrestricted free slanting brush strokes upward in the snow covered area and two dry brush strokes of black and blue apart give an effect of a slope. 


\section{PLATE 23}

Triptych (three seasons) of Plates 20, 21, and 22

PLATE 24

Spring is a symbol of hope. Therefore, an attempt was made to show a hopeful season by using many delightful spring colors. The strokes made here look like all the creatures breaking out of the soil. Here, two paintings expressing Spring were combined into a diptych. The expression of the sky looks so cheerful with the reflections from the colorful mountain.

\section{PLATE 25}

Plate 25 is simply an abstract form of leaves and tree branches. The left half is composed of all kinds of abstract forms of leaves and the right half is composed of forms of branches. This right half is the scene of bare tree branches without leaves being seen from a window. The background between the tree branches symbolizes the bright, blue sky. Before painting on this canvas, it was divided into three geometric areas: square, triangle, and semi-circle. 


\section{PIATE 26}

In Plate 26, it was my intention to produce texture and the harmony of colors. I think that beauty can be created out of forms and color combinations regardless of meaning or expression--in other words, an art independent of ideas and composed in terms of aesthetic attraction by the abstract arrangement of the elements comprising the picture.

Thus, in Plate 26, an attempt was made to build up a rich surface texture, using plaster or gesso and flour glue mixed together. It is not always an easy task to combine subject matter and form, and in some instances a painting can be good without both of these being present.

To me, a living abstract, a painting with good qualities of surface texture and color, can be more exciting and vitally alive than a picture of a specific subject. I think that if the message the artist tries to communicate is worthwhile, or the methods employed convey meaning in themselves, then the painting will be successful regardless of the style, and the art will live on. In this sense, I titled this subject "Non-titled." 


\section{PLATES $27 \& 28$}

Plate 27, St. John's bridge and Plate 28, Marquam bridge are considered the two most beautiful bridges connecting two different areas. Plate 27, St. John's bridge, simply shows many graceful vertical lines in the bridge span; Marquam bridge is very proud of not only its importance for a main traffic flow, but also for its beautiful curved lines. In Marquam bridge, Plate 28, all the curved Iines involving the bridge were executed with Oriental brushes and then colors were added with a wide bristle brush. I chose these two bridges, because it was very interesting for me to contrast the vertical lines on the St. John's bridge and the curved horizontal lines on the Marquam bridge. 
III. MIXED MEDIA

PLATE 29

Plate 29 was painted on rice paper covered masonite board, the background of which was not painted except for the wedge strokes around the bottom area. This was painted by means of Oriental technique to express these flowers.

\section{PLATE 30}

Plate 30 , Flowers by the lake, was painted not on a masonite board, but on the old painting over which a sheet of rice paper was pasted. This is to show the contrasting point between the vertical strokes of "Soo sun Wha" and the round shaded strokes of "San Da Wha". This is a painting with attention given particularly to Western style of composition and Oriental brush strokes.

\section{PLATE 32}

In Plate 31, two paintings of pine trees were combined into a diptych. The pine tree expressed by the use of Oriental technique and the color harmony in the background are a good combination of Far Nast and West in techniques. The whole picture has a sense of motion and mysterious feeling, the motion being that of a circular movement. 


\section{PLATE 32}

Plate 32, A flock of birds in the shrub, was painted on an old painting over which one sheet of rice paper was pasted with glue made out of flour. I discovered that it is wiser to start painting on it after the rice paper dries up. Otherwise, the color may look discolored afterwards. Exclusively Oriental brush strokes were used.

\section{PLATE 33}

Plate 33, Seascape was washed with blue and one coat of thin gesso was horizontally applied with a wide brush. Consequently, the whole canvas was in a state of wet, which helped produce textures around the moons by scratching with charcoal. Warm and cool were mingled from front toward the horizontal line. The orange and blue painted with pastel was rubbed lightly with a piece of cloth so that this may look much smoother. The white paint is gesso. Pastel used in between gives handsome textures that could not be gained any other way.

\section{PLATE 34}

Plate 5, Landscape, was sketched from memory impression. This simple theme gave a chance for the brush to move freely and for the artist to find fresh inspiration in nature. It is fresh and spontaneous and executed with simplicity of style. The sky was painted with silver. 


\section{PLATE 35}

Plate 35, Marquam bridge sketched from one of the view spots overlooking the Willamette River was painted with tempera and black ink. On this particular painting, an Oriental brush was exclusively used and then a piece of stick was used to give accent to the buildings in the background and curved lines on the bridge. Fach curved line involving the bridge was done with just one long brush stroke without the brush raised from the canvas. Since the rough side of the rice paper covered masonite board was used, good textures could be obtained easily.

\section{PLATE 36}

Plate 36, Quiet, has a little touch of Oriental and Western taste in composition in that there is space unpainted between and around the painting. The colors blended were not executed on the canvas, but the wide Western bristle brush was dipped in several colors, thereby producing broad streaks of firm strokes--dry thick brush strokes. Even the dynamic brush strokes on the background and the unpainted white area helped create an atmosphere of profound calm. 
ORIEXTAI PAINING 

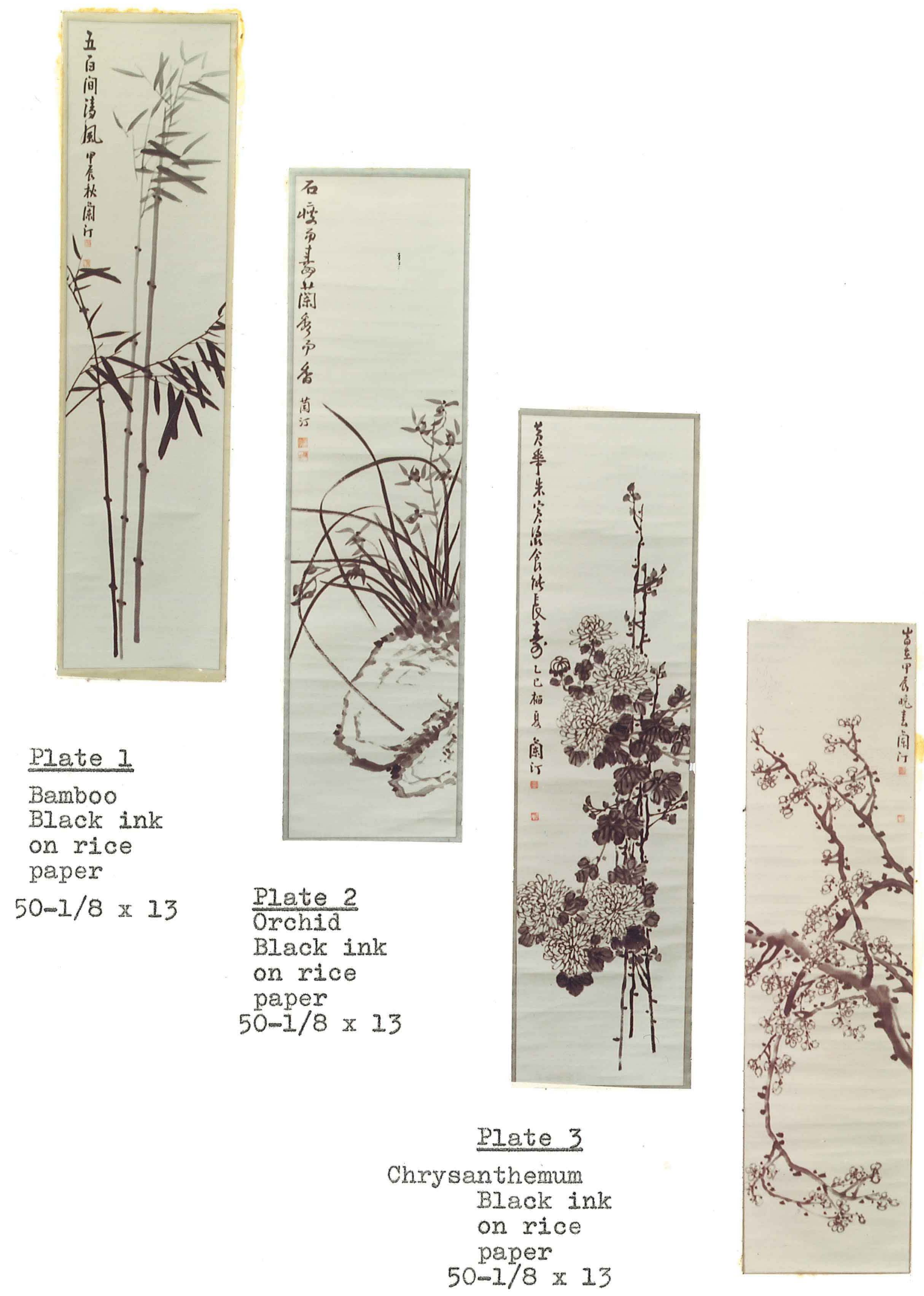

Plate 4

PIum-blossoms Black ink

on rice paper $50-1 / 8 \times 13$ 


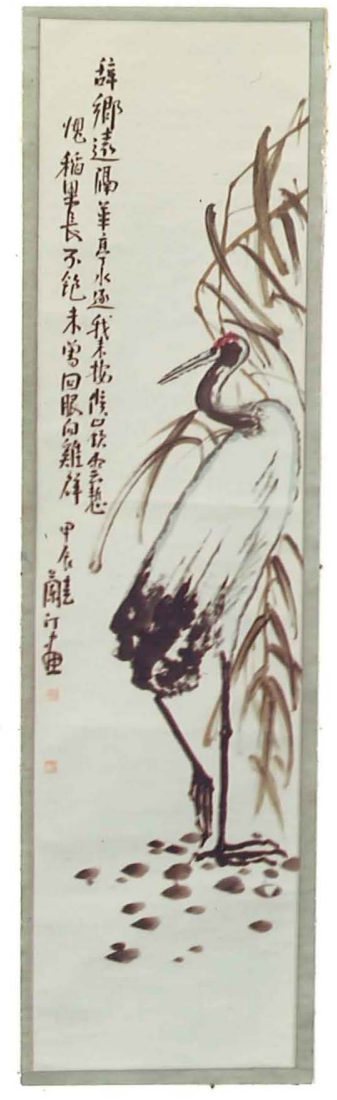

\section{Plate 5 \\ Crane \\ Black ink on rice paper \\ $50-1 / 2 \times 13$}

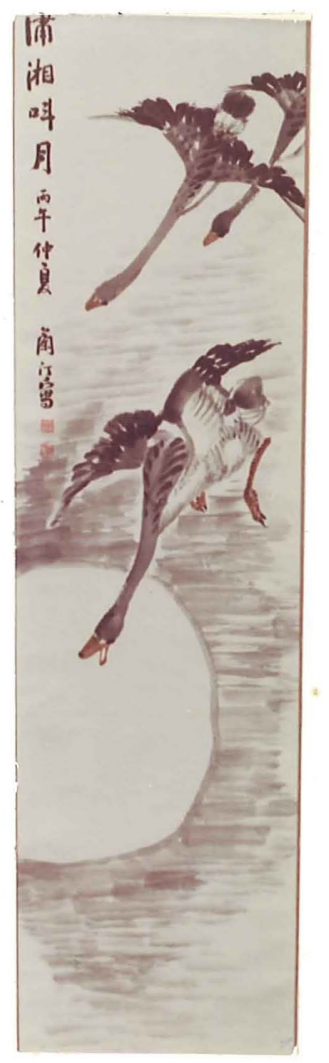

Plate 6

Wild Geese

Black ink on rice paper

$49-1 / 4 \times 13$ 


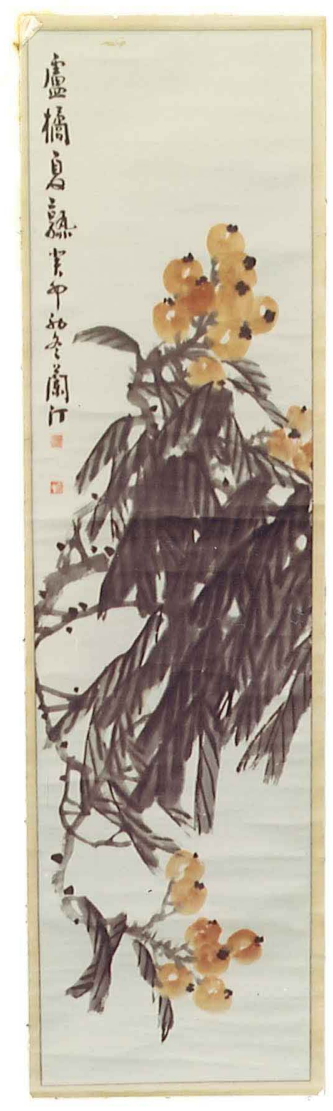

\section{Plate 7}

Ioquat

Water color

on rice paper

$50-1 / 8 \times 13$

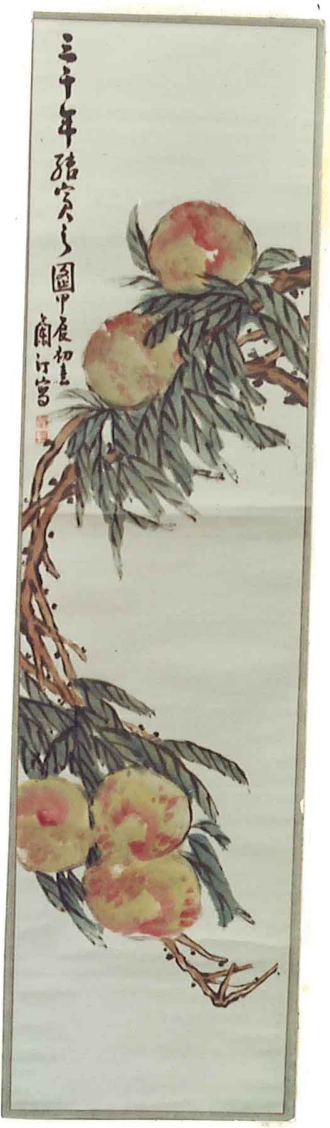

Plate 8

Peaches Water color on rice paper $50-1 / 8 \times 13$ 


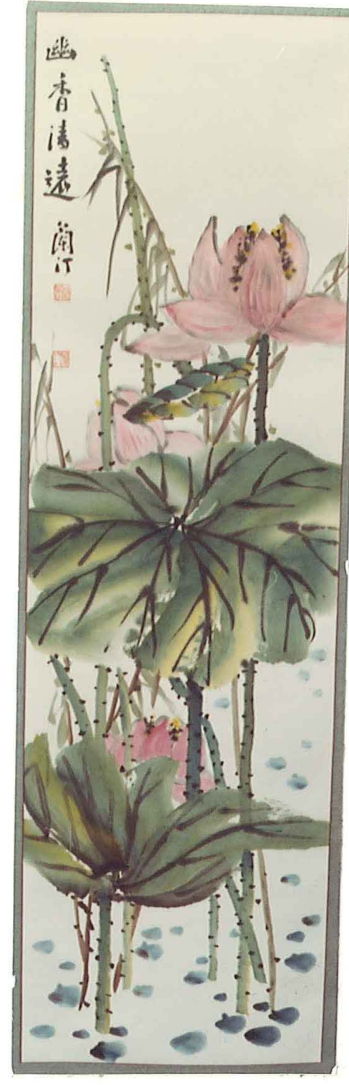

Plate 9

Lotus

Water color

on rice paper

$36-1 / 2 \times 11$

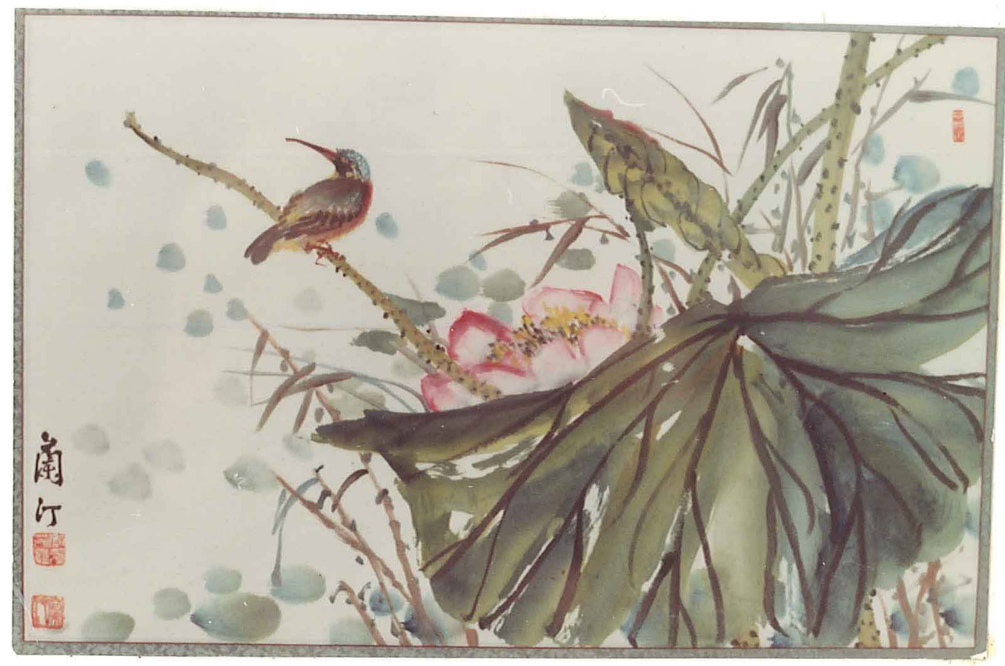

Plate 10

Birds and Lotus

Water color on rice paper

$16-3 / 4 \times 11$ 


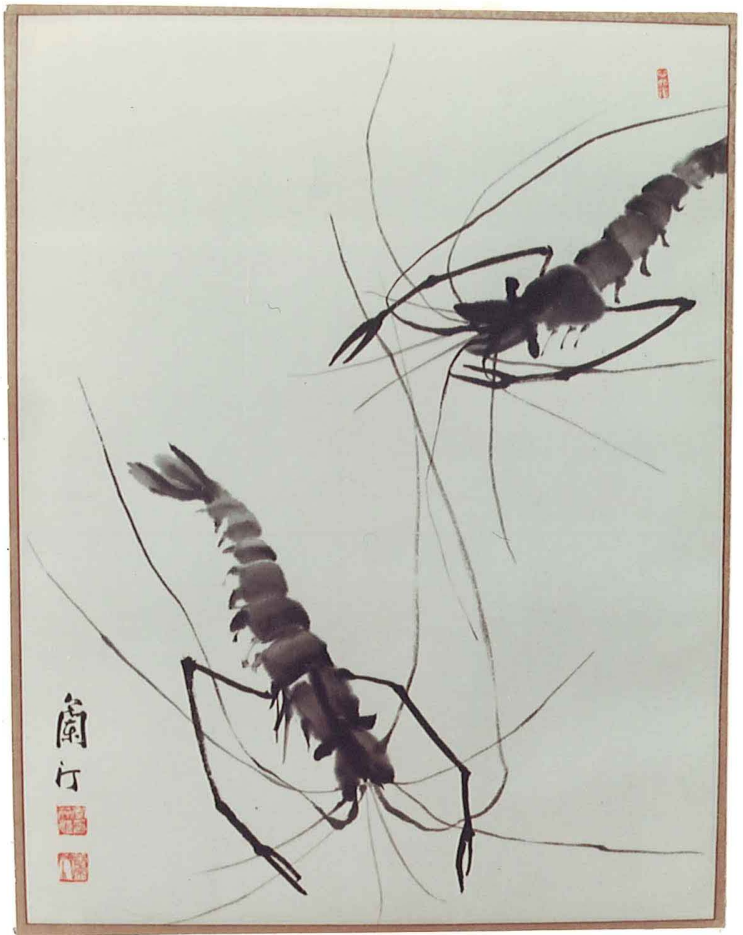

Plate 11

Black ink on rice paper

$13 \times 17$

Lobster 


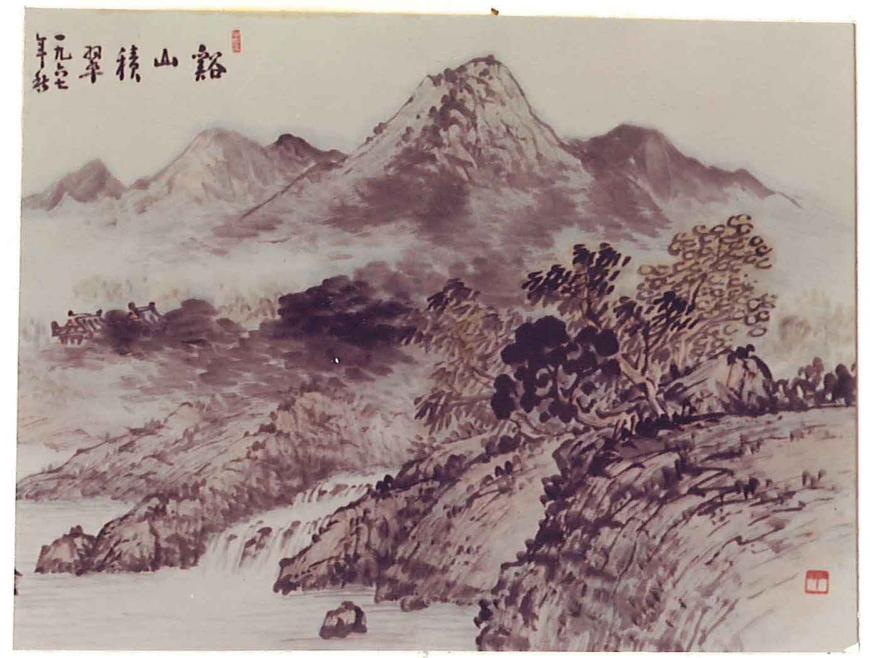

Plate 12

Irandscape

Water color on rice paper

$17 \times 25-1 / 2$

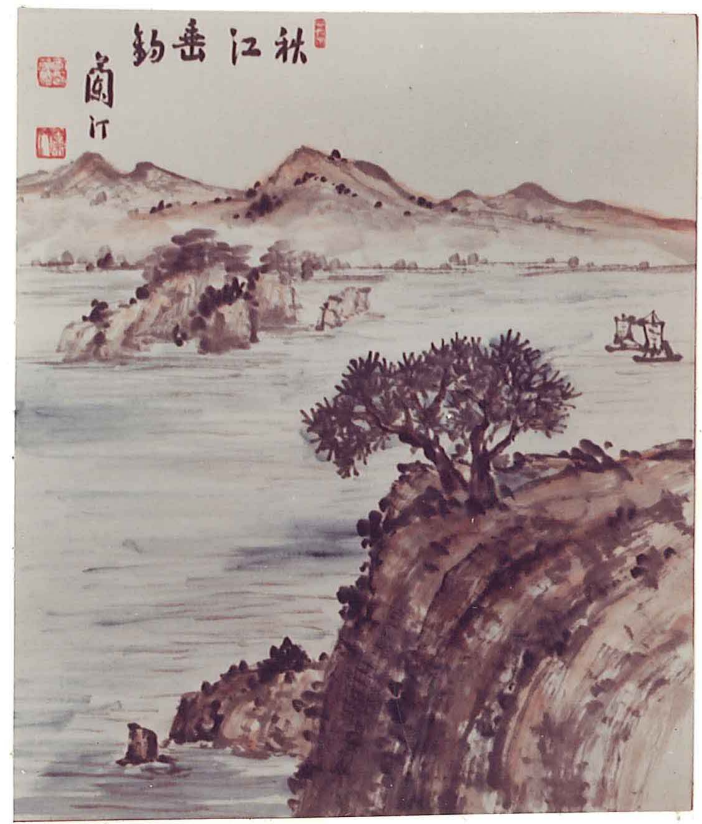

Plate $12-1$

Land scape Water color on rice paper $23 \times 17$ 


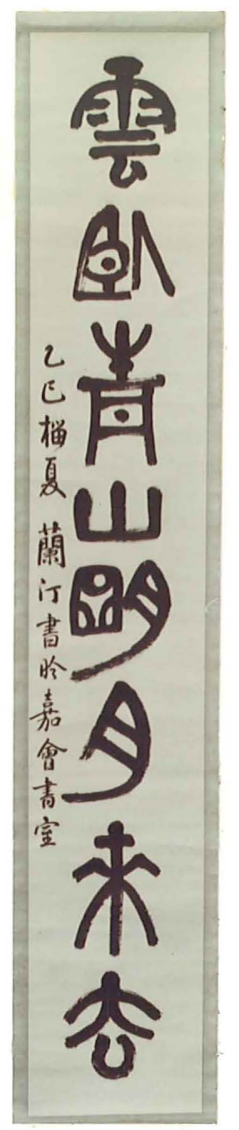

Plate 13

\section{Chinese}

Calligraphy

Black ink

on rice paper

$50-3 / 4 \times 7-3 / 4$

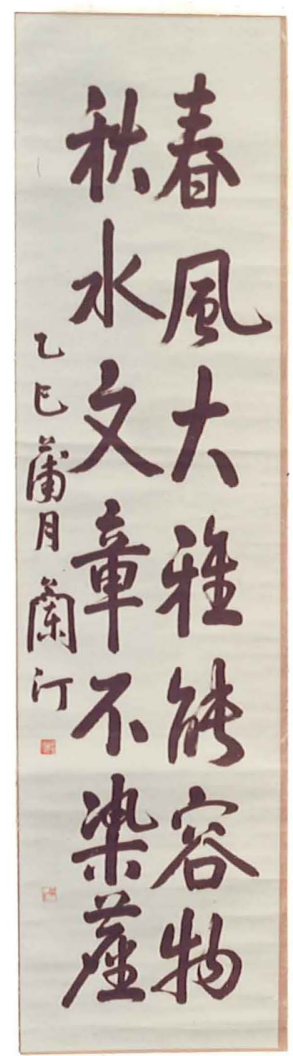

Plate 14

Chinese

Calligraphy

Black ink

on rice paper

$50 \mathrm{~m}-1 / 2 \times 13$ 

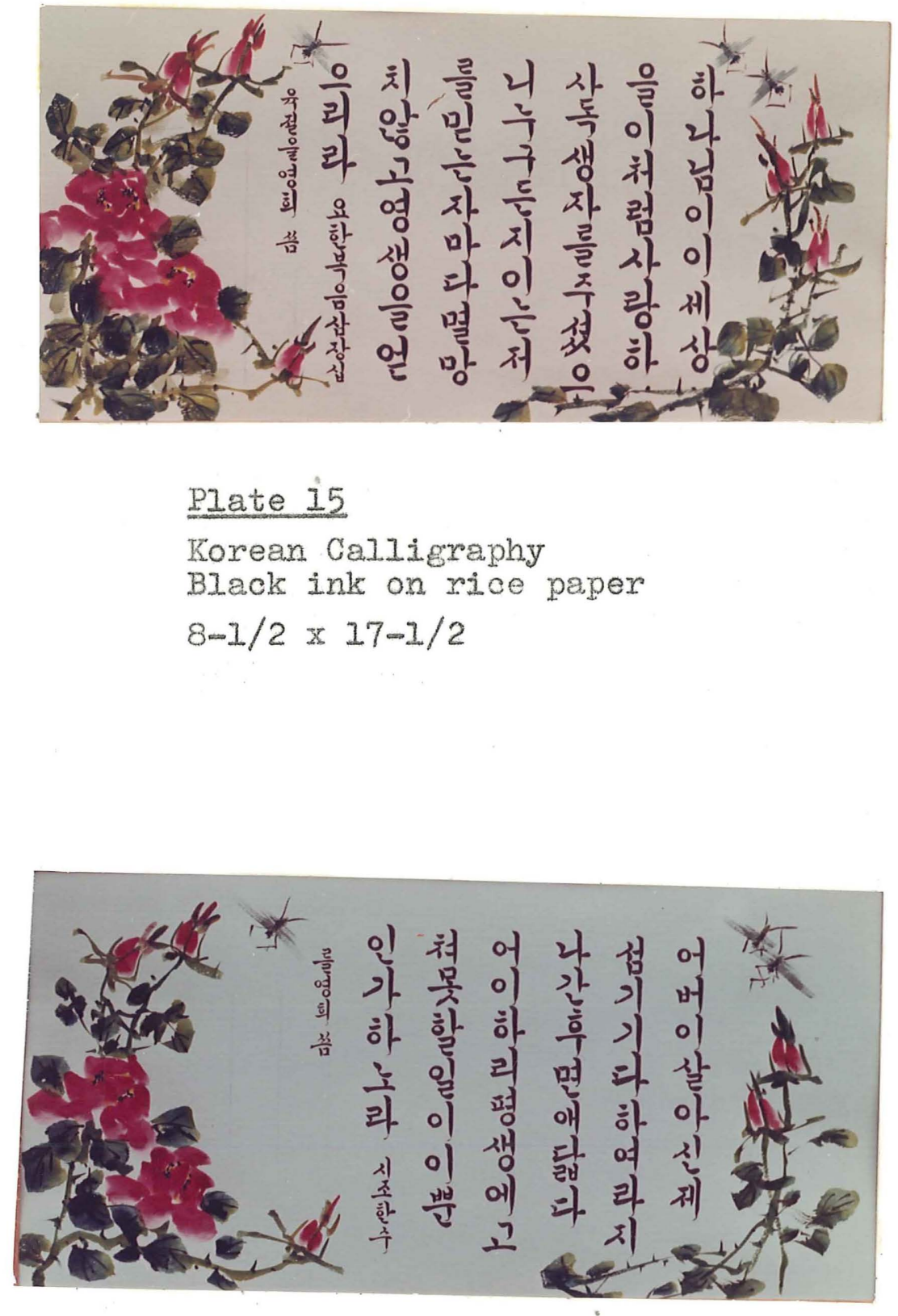

Plate 16

Korean Calligraphy

Black ink on rice paper

$8-1 / 2 \times 17-1 / 2$ 


\section{WESTERN PAINTINC}




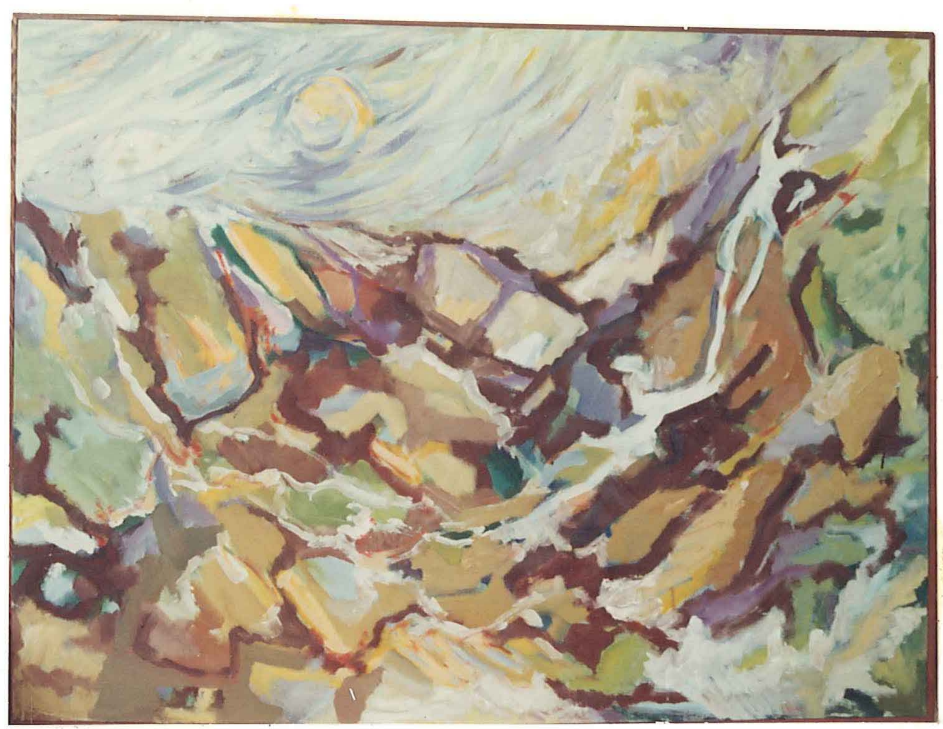

Plate 17

Autumn

Oil on canvas

$36-3 / 4 \times 48$

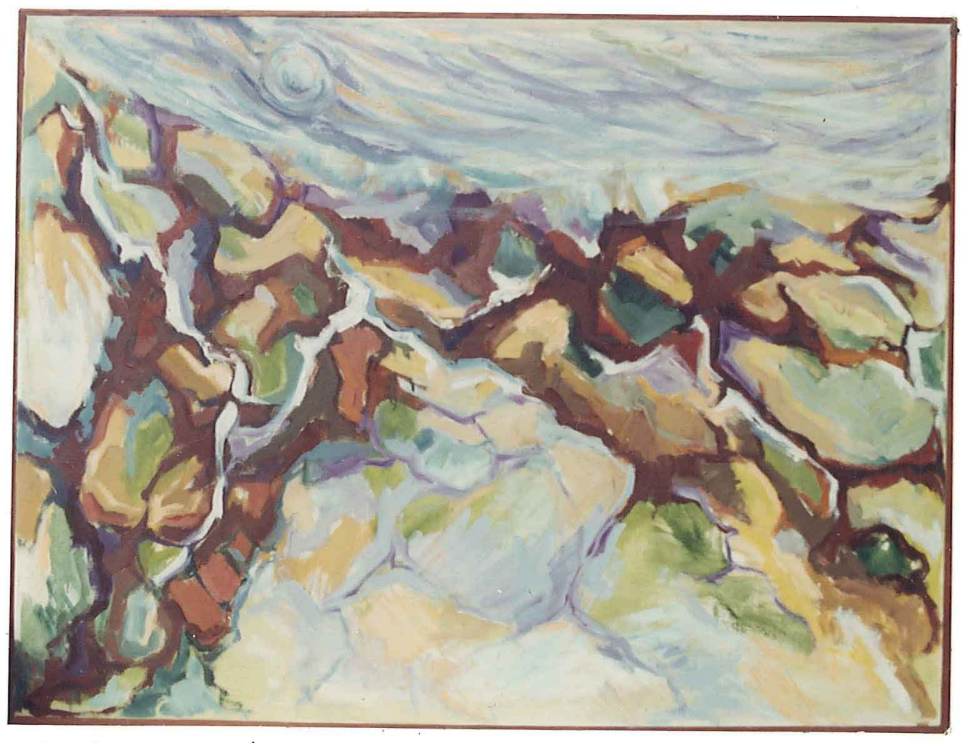

Plate 18

Autumn

0il on canvas

$36-3 / 4 \times 48$ 


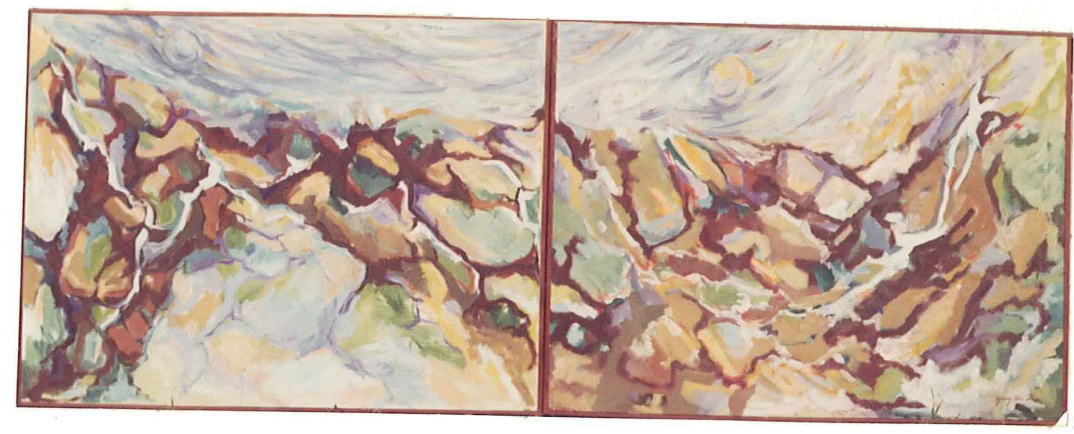

Plate 19

Autum Diptych

oil on canvas

$73-1 / 2 \times 96$ 


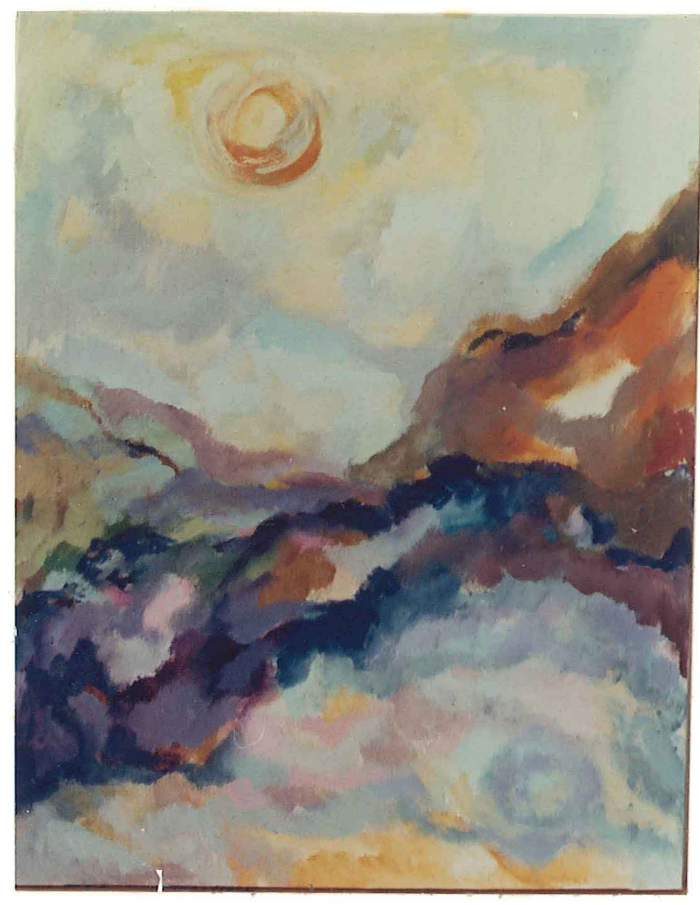

Plate 20

Summer

Oil on canvas

$20 \times 26$

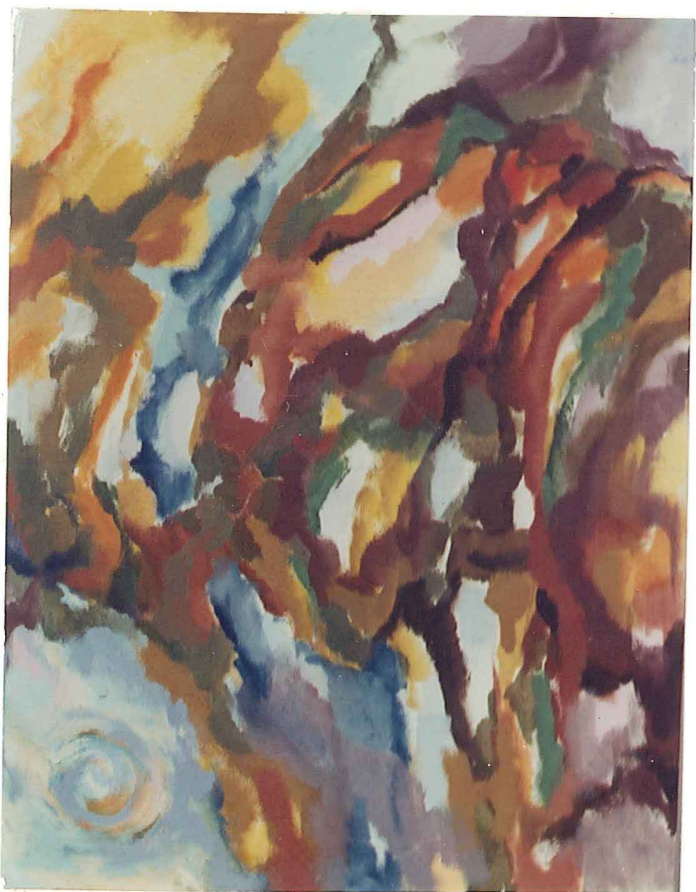

Plate 21

Autumn

011 on canvas

$20 \times 26$

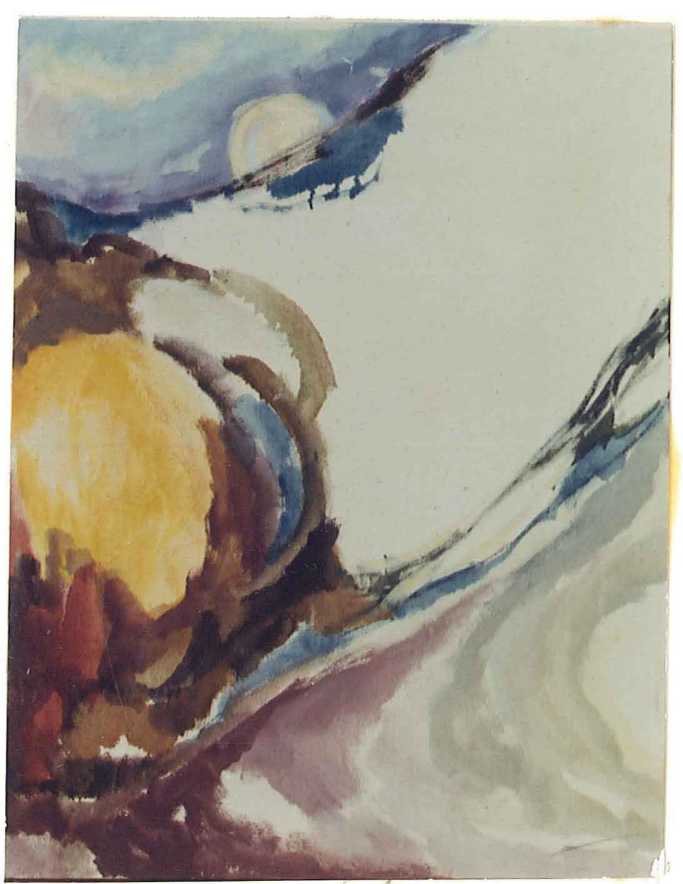

Plate 22

Winter

Oil on canvas

$20 \times 26$ 


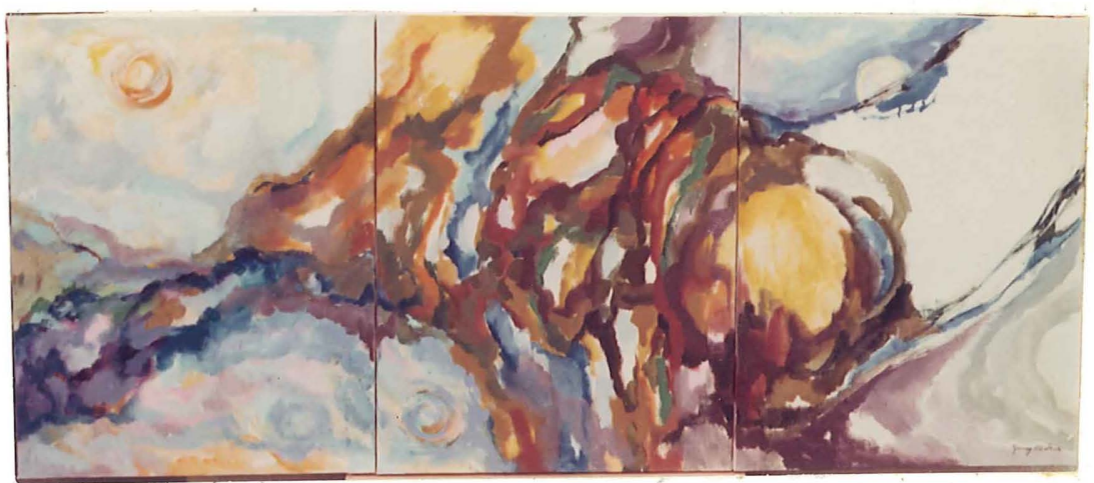

Plate 23

Three Seasons Triptych

011 on canvas

$60 \times 78$ 


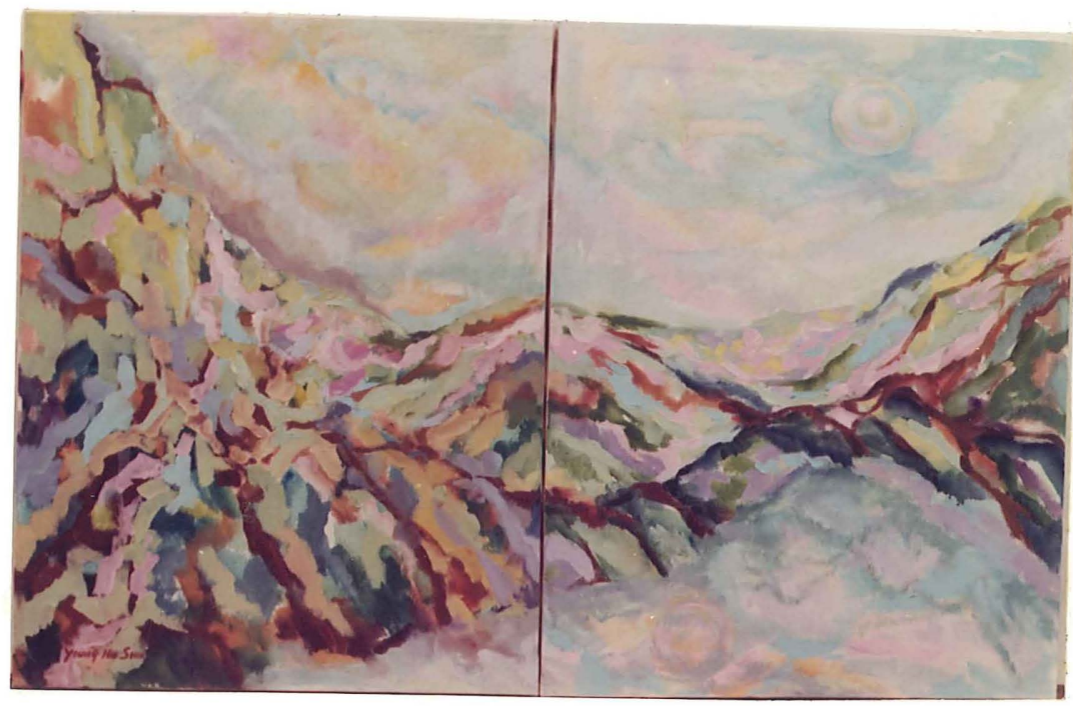

Plate 24

Spring Diptych

Oil on canvas

$40 \times 52$ 


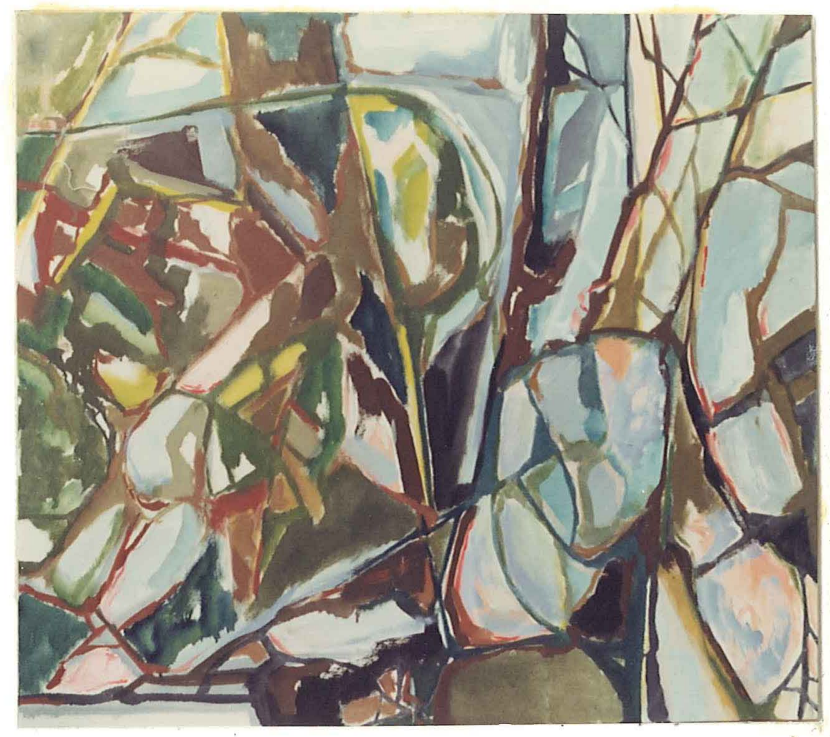

Plate 25

Leaves and Branches

Oil on canvas

$28 \times 31$

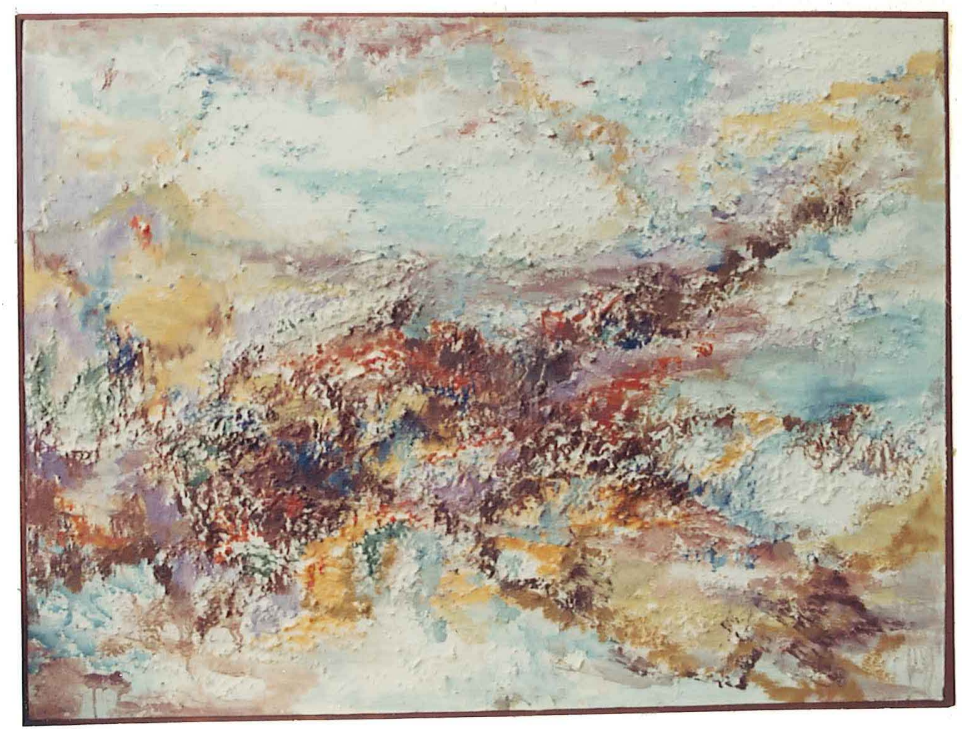

Plate 26

Non-titled

O1I on plastered canvas

32. $\times 42$ 


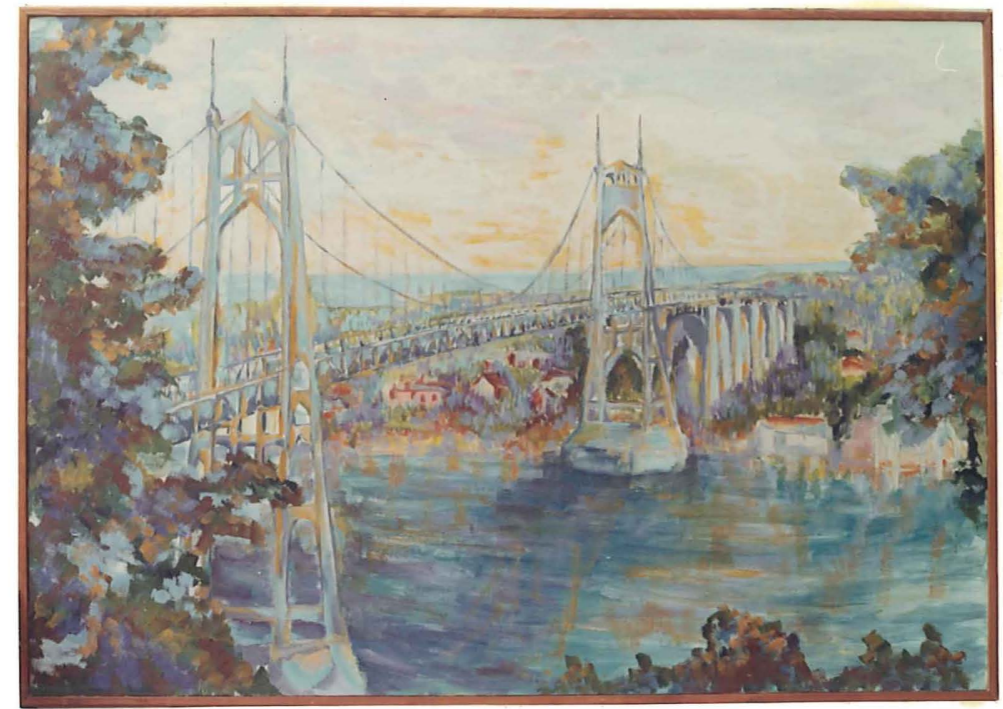

Plate 27

St. John's Bridge

Oil on canvas

$34 \times 48$

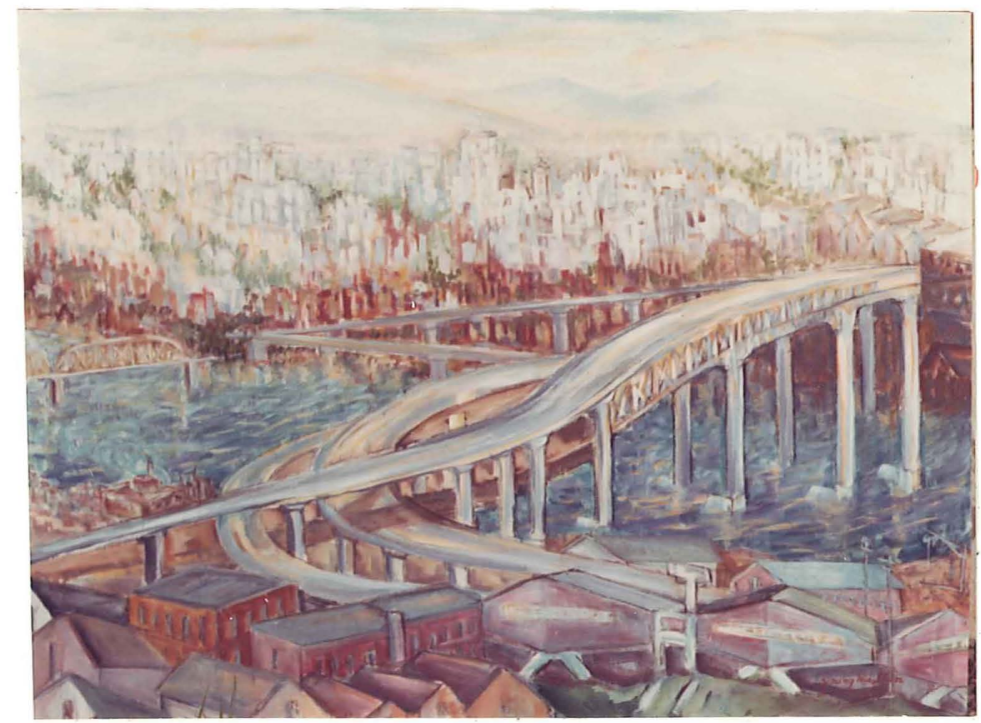

Plate 28

Marquam Bridge

Oil on canvas

$36 \times 48$ 
MIXED MEDTA 


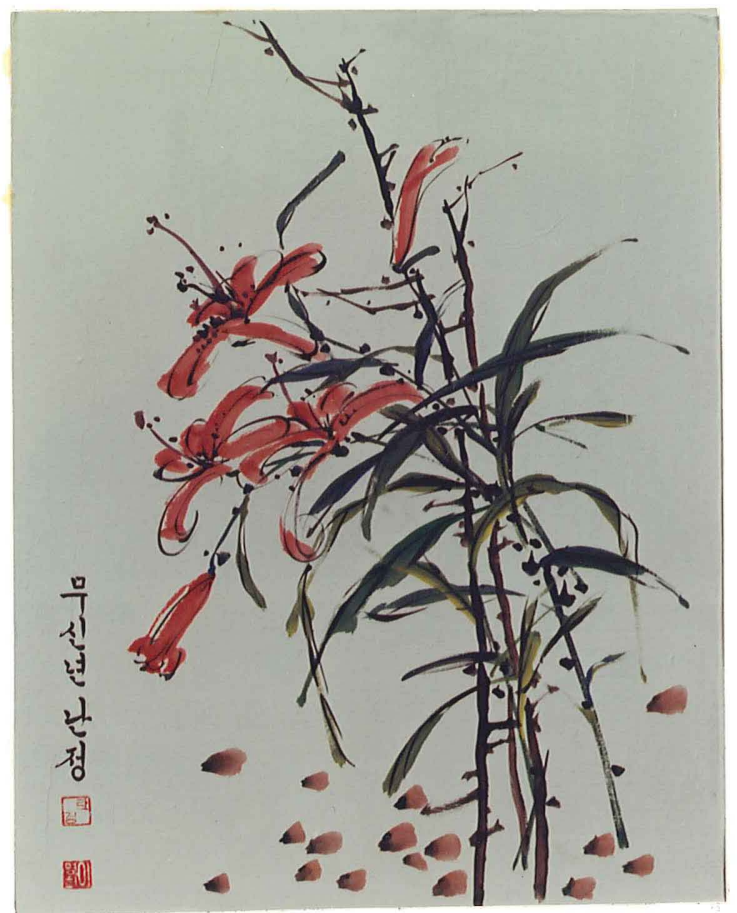

Plate 29

Wild LiIy

Tempera on rice paper

$18 \times 23$

Plate 30

Plowers by the

lake

Tempera \& Oil

on rice papered canvas

$27-5 / 8 \times 36-3 / 8$

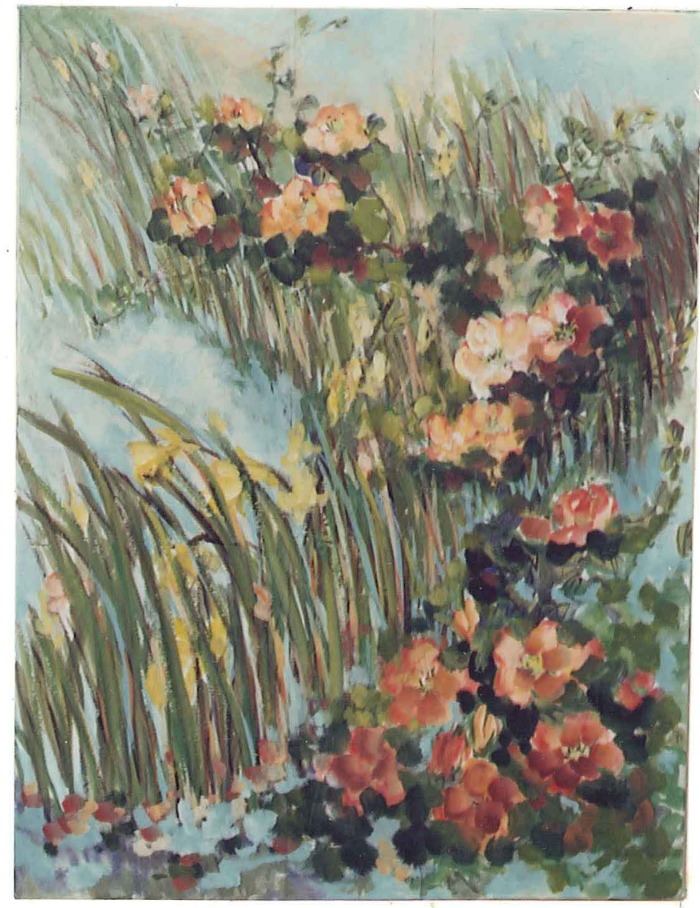




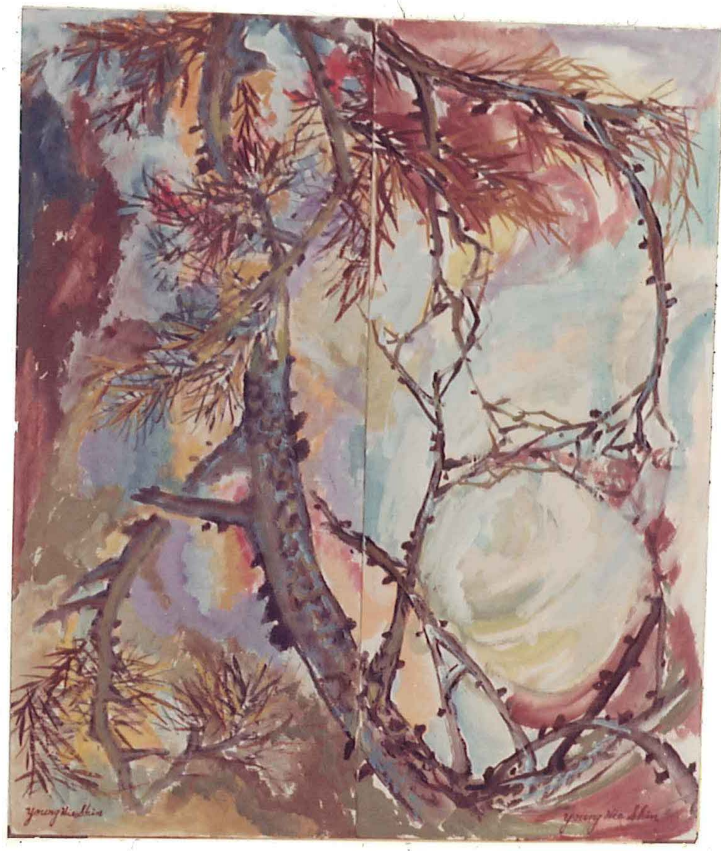

Plate 31

Pine Tree

Tempera on rice papered masonite board

$28 \times 66$ 


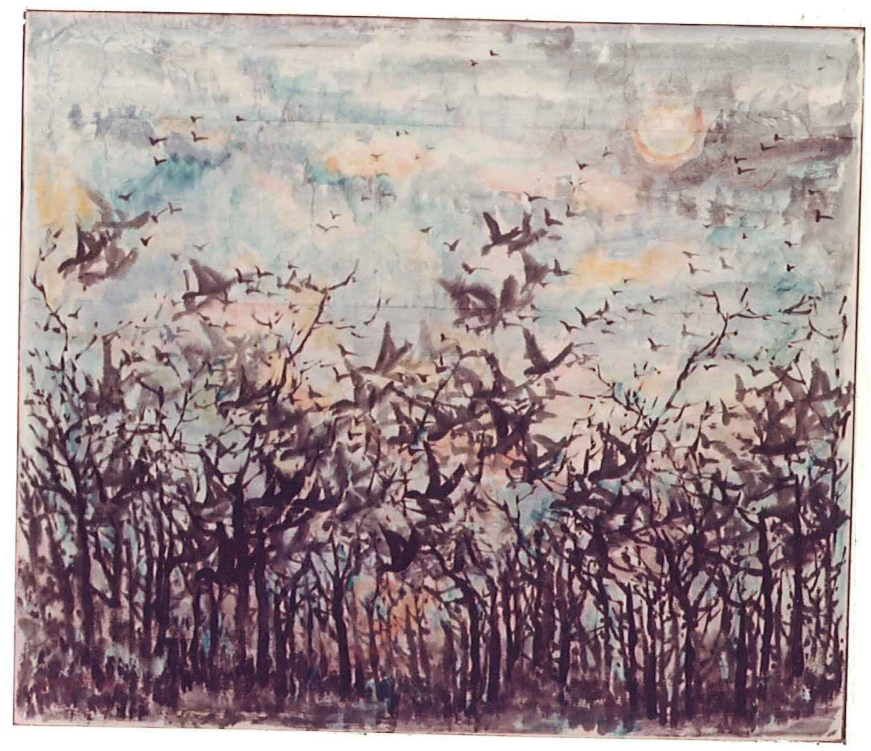

Plate 32

A Flock of Birds in the shrub Black ink and Tempera on rice papered canvas

$37 \times 43$ 


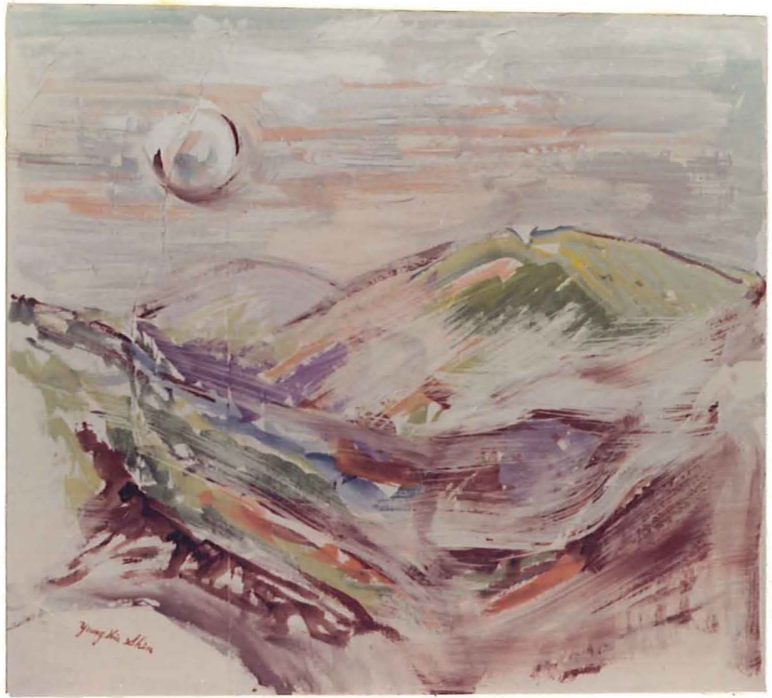

Plate 33

Iand scape

Tempera and gesso on

rice papered masonite $22-7 / 8 \times 25$

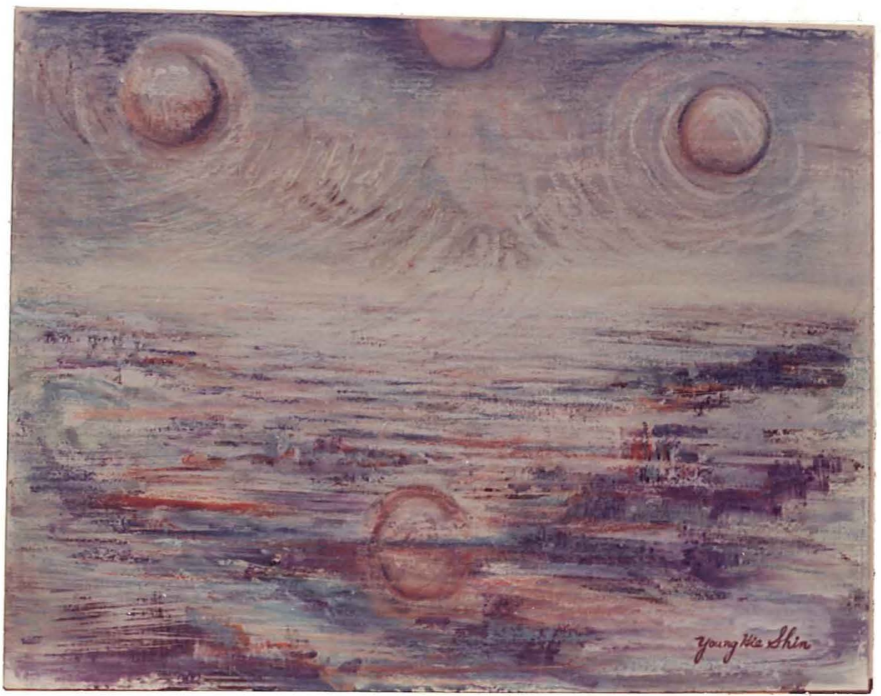

Plate 34

Seascape

Tempera, 0il, \& Pastel

on rice papered masonite

$18 \times 23$ 


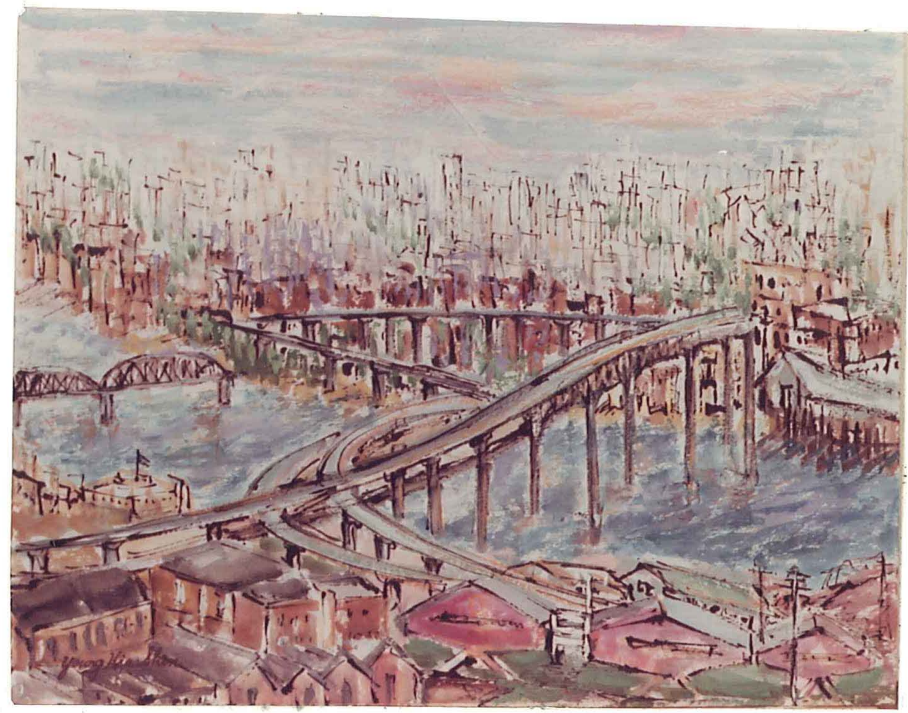

Plate 35

Marquam Bridge

Tempera on rice papered masonite $18 \times 23$ 


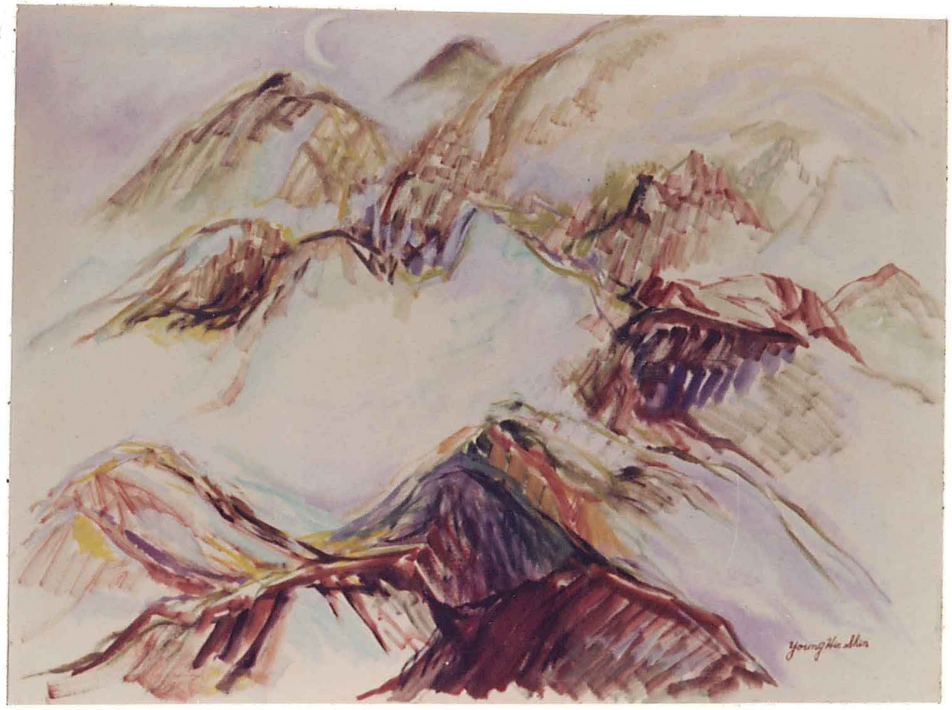

Plate 36

Quiet

OII and Tempera

on canvas

$36-1 / 4 \times 48$ 